\title{
Cutaneous Adverse Drug reactions: A Four-Year Study from Western Nepal
}

\author{
Neupane $\mathrm{S}^{1^{*}}$, Basnet $\mathrm{B}^{2}$ \\ ${ }^{1}$ Associate Professor, ${ }^{2}$ Assistant Professor, \\ Department of Dermatology, Gandaki Medical College \& Teaching Hospital, Pokhara, Nepal
}

\section{Keywords \\ Antibacterial agents, Cefixime, \\ Exanthema, Stevens-Johnson syndrome \\ Corresponding author \\ *Dr. Saraswoti Neupane MBBS MD \\ Associate Professor \\ Department of Dermatology \\ Gandaki Medical College \& Teaching \\ Hospital, Pokhara, Nepal \\ Email: sarunpn@gmail.com}

\begin{abstract}
Background: Cutaneous adverse drug reactions (CADRs) range from minor reactions to several life threatening complications.

Objectives: To study the clinical spectrum of cutaneous adverse drug reactions, determine the causative drugs responsible for the reactions and to assess the preventability.

Methods: The study was carried out in the Department of Dematology of Gandaki Medical College Teaching Hospital from June 2011 to June 2015. All the patients attending the Dermatology Outpatient Department and the patients admitted in the wards with suspected cutaneous adverse drug reactions to systemic drugs were included in the study. A detailed clinical history, including the history of drug intake was noted. Each case was assessed for its causality by using the WHO definitions. Data analysis was done using SPSS software.
\end{abstract}

Results: There were 102 patients in total. The mean age of the patient was $32 \pm 15.7$ years. Maximum patients belonged to the 21 to 30 years age group. There were 59 female patients and 43 male patients. Severe type of cutaneous adverse drug reactions was noted in $7.8 \%$ of patients. Antibiotics were responsible for most of the cutaneous adverse drug reactions. Cefixime was the most commonly incriminated drug. Exanthematous drug reaction was the most common type seen in $45 \%$. Stevens-Johnson syndrome was the commonest type noted among the serious adverse drug reactions. Drug preventability was noted in $6 \%$ of patients.

Conclusions: The commonest type of CADR noted was exanthematous type. Antibiotics were the commonest drug group involved in CADR. Six percent of CADR were preventable.

\section{INTRODUCTION}

Drug reactions are the unwanted effects on the body exerted by the drugs, which are not the characteristic of the desired pharmacodynamic effects ${ }^{1}$. Cutaneous adverse drug reactions (CADRs) range from minor reactions to several life threatening complications. They are often under reported because of their resemblance with viral exanthemas, collagen vascular diseases and neoplastic processes. A high index of suspicion is required for the prompt diagnosis so that the culprit drug is withdrawn as early as possible and the treatment initiated early to prevent a grave outcome. The list of drugs causing a particular type of reaction is ever expanding due to the introduction of newer drugs for the treatment of diseases. 
This prospective study was conducted to study the clinical spectrum of cutaneous adverse drug reactions, determine the causative drugs responsible for the reactions and to assess the preventability.

\section{METHODS}

It was a prospective descriptive study carried out over a period of four years from June 2011 to June 2015 in the Department of Dermatology of Gandaki Medical College Teaching Hospital, Pokhara, Nepal. All the patients attending the Dermatology Outpatient Department and the patients admitted in the wards with suspected cutaneous adverse drug reactions to systemic drugs were included in the study. Prior approval was obtained from the Institutional review committee. Informed consent was obtained from each patient in our study. Cutaneous adverse drug reactions caused by the use of topical medications were excluded from the study. Data collection was done in a preset proforma that included the demographic details of the patients and a detailed clinical history. A detailed history of drug intake, reaction time, previous history of drug reaction, duration of reaction, type of cutaneous reaction, and improvement after the dechallenge were noted. Relevant investigations were done to rule out any infectious etiology. The reaction was considered as preventable if a previous exposure to the suspected causative drug(s) or another drug of the same family had already caused an adverse skin eruption.

Each case was assessed for its causality by using the WHO definitions and was categorized as 'certain', 'probable', 'possible', 'unlikely', 'conditional/ unclassified' and 'unassessable /unclassifiable'2. Only the 'certain' and 'probable' cases were included in the study. Data analysis was done using SPSS software.

\section{RESULTS}

According to the census, there were altogether 31,396 patients in the Department of Dermatology in four years period, including the outpatients and inpatients. Among them, 102 patients were diagnosed with cutaneous adverse drug reactions. So, the incidence of cutaneous drug reaction was $0.32 \%$. The mean age of the patient was $32 \pm 15.7$ years. Age of the patients ranged from one to 77 years. Maximum patients belonged to the 21 to 30 years age group (Table 1). There were 59 (58\%) female patients and $43(42 \%)$ male patients. Eight patients $(7.8 \%)$ had severe type of cutaneous adverse drug reactions and the remaining had milder CADR.

Table 1: Age distribution of patients

\begin{tabular}{lcc}
\hline Age group (Years) & Frequency & Percentage \\
\hline Up to 10 & 6 & $5.9 \%$ \\
$11-20$ & 17 & $16.7 \%$ \\
$21-30$ & 32 & $31.4 \%$ \\
31 - 40 & 25 & $24.5 \%$ \\
$41-50$ & 9 & $8.8 \%$ \\
$51-60$ & 6 & $5.9 \%$ \\
$61-70$ & 5 & $4.9 \%$ \\
$71-80$ & 2 & $2.0 \%$ \\
Total & 102 & $100.0 \%$ \\
\hline
\end{tabular}

Table 2: Clinical pattern of cutaneous adverse drug reactions

\begin{tabular}{|c|c|c|}
\hline Type of drug reaction & Frequency & Percentage \\
\hline Exanthematous & 46 & $45.1 \%$ \\
\hline Fixed drug eruption & 17 & $16.7 \%$ \\
\hline Photosensitivity & 8 & $7.8 \%$ \\
\hline Urticaria & 7 & $6.9 \%$ \\
\hline Steven-Johnson syndrome & 5 & $4.9 \%$ \\
\hline Hair loss & 4 & $3.9 \%$ \\
\hline Pityriasis rosea & 2 & $2.0 \%$ \\
\hline Pigmentation & 2 & $2.0 \%$ \\
\hline Pruritus & 2 & $2.0 \%$ \\
\hline AGEP & 1 & $1.0 \%$ \\
\hline Purpura & 1 & $1.0 \%$ \\
\hline Acneiform & 1 & $1.0 \%$ \\
\hline Urticarial vasculitis & 1 & $1.0 \%$ \\
\hline Psoriasiform & 1 & $1.0 \%$ \\
\hline Lichenoid & 1 & $1.0 \%$ \\
\hline Erythroderma & 1 & $1.0 \%$ \\
\hline Toxic epidermal necrolysis & 1 & $1.0 \%$ \\
\hline DRESS & 1 & $1.0 \%$ \\
\hline Total & 102 & $100 \%$ \\
\hline
\end{tabular}

AGEP: Acute generalized exanthematous pustulosis 
Table 3: Drugs causing cutaneous adverse drug reactions

\begin{tabular}{|c|c|c|c|c|}
\hline & Females & Males & Total & $\begin{array}{c}\text { Per- } \\
\text { centage }\end{array}$ \\
\hline Antibiotic & 25 & 22 & 47 & $46.07 \%$ \\
\hline NSAIDs & 8 & 10 & 18 & $17.64 \%$ \\
\hline Anticonvulsant & 11 & 5 & 16 & $15.68 \%$ \\
\hline DMARD & 4 & & 4 & $3.92 \%$ \\
\hline Antidepressant & 1 & 2 & 3 & $2.94 \%$ \\
\hline Diuretic & 2 & & 2 & $1.96 \%$ \\
\hline ATT & & 2 & 2 & $1.96 \%$ \\
\hline Antipsychotic & 1 & & 1 & $0.98 \%$ \\
\hline Antigout (Allopurinol) & 1 & & 1 & $0.98 \%$ \\
\hline Mood stabilizer & 1 & & 1 & $0.98 \%$ \\
\hline ATT & 1 & & 1 & $0.98 \%$ \\
\hline Ayurvedic & 1 & & 1 & $0.98 \%$ \\
\hline Proton pump inhibitor & 1 & & 1 & $0.98 \%$ \\
\hline Urso deoxycholic Acid & 1 & & 1 & $0.98 \%$ \\
\hline Anticoagulant & 1 & & 1 & $0.98 \%$ \\
\hline Oral hypoglycemic agent & & 1 & 1 & $0.98 \%$ \\
\hline Antifungal & & 1 & 1 & $0.98 \%$ \\
\hline Total & 59 & 43 & 102 & $100 \%$ \\
\hline
\end{tabular}

ATT: Anti tubercular treatment DMARD: Diseasemodifying antirheumatic drug

The most common group of drugs involved in CADR was antibiotics. Among antibiotics, maximum frequency of drug reaction was seen with $\beta$ lactam antibiotics, penicillin (36\%) and cephalosporin (32\%). Amoxycillin was the commonest penicillin and cefixime was the commonest cephalosporin causing CADRs. Overall, cefixime caused most of the CADRs. Other antibiotics were ciprofloxacin, levofloxacin, cotrimoxazole, doxycycline, metronidazole and ornidazole. Non steroidal anti-inflammatory drug (NSAID) was the second most common category of drug involved. Among the NSAIDs, the most of the drug reactions were noted with nimesulide, followed by diclofenac. The third common group of drug involved was anticonvulsant and the commonest anticonvulsant involved was phenytoin. Disease-modifying antirheumatic drugs (DMARDs) contributed to around $4 \%$ of CADR (Table 3).

The three most common types of drug reactions were exanthematous type (45\%), fixed drug eruption (17\%) and drug induced photosensitivity (8\%). Other types of CADR were urticarial, Stevens-Johnson syndrome (SJS), hair loss, pitytriasis rosea, pruritus, pigmentation, purpura, acute generalized exanthematous pustulosis, acneiform eruptions, urticarial vasculitis, psoriasiform eruption, lichenoid eruption, erythroderma, toxic epidermal necrolysis (TEN) and DRESS syndrome. Among the severe types of drug reactions, maximum cases were of SJS (Table 2). The most common type of drug reactions observed in paediatric age group ( $<14$ years age group) was exanthematous drug reaction followed by fixed drug eruption. Other types noted in the paediatric age group were urticarial drug eruption, pruritus, erythroderma and SJS (Table 4).

Table 4: Relationship between the drug and cutaneous adverse drug reaction

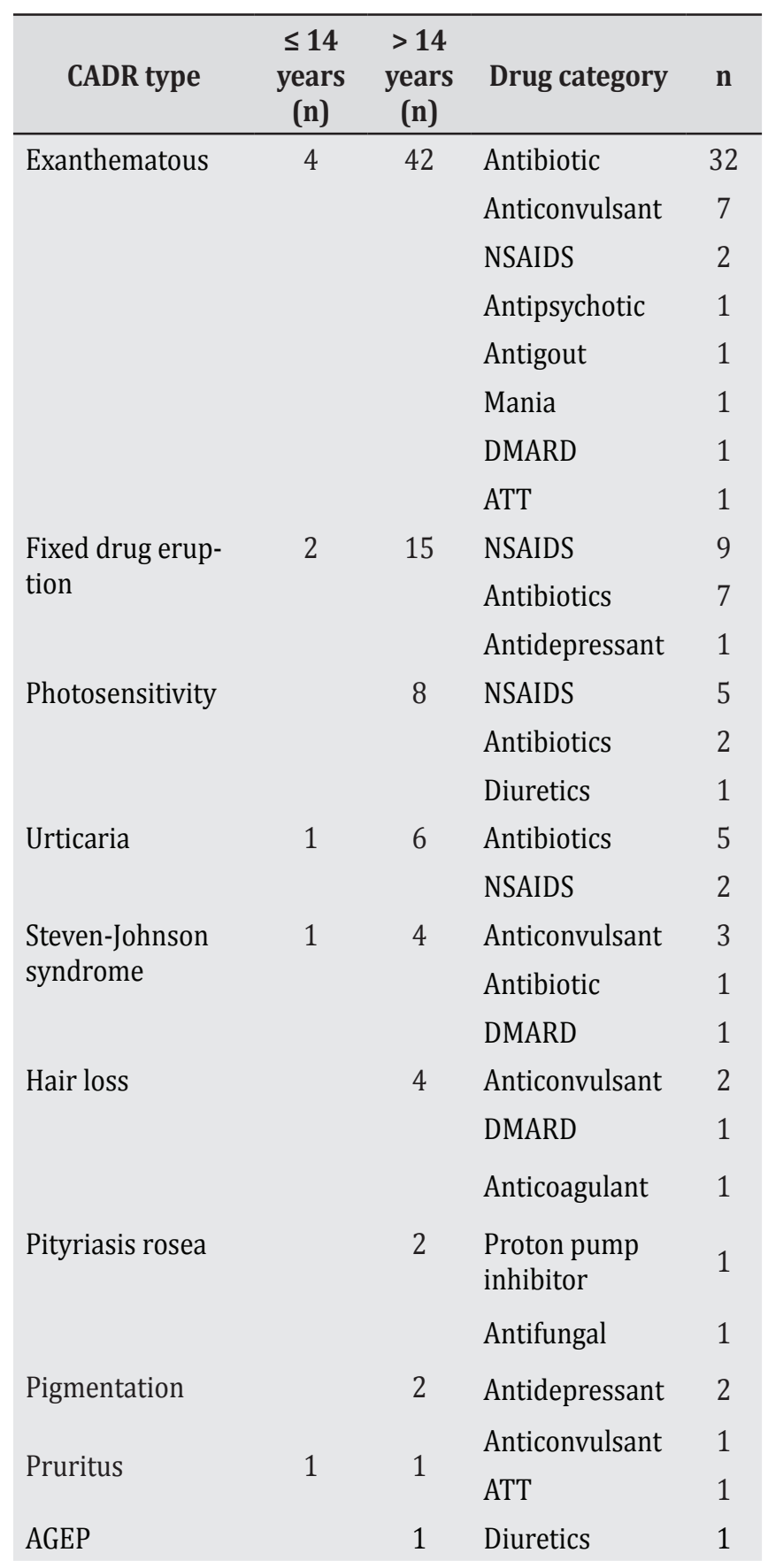




\begin{tabular}{|c|c|c|c|c|}
\hline CADR type & $\begin{array}{c}\leq 14 \\
\text { years } \\
\text { (n) }\end{array}$ & $\begin{array}{c}>14 \\
\text { years } \\
\text { (n) }\end{array}$ & Drug category & n \\
\hline Purpura & & 1 & Anticonvulsant & 1 \\
\hline Acneiform & & 1 & Anticonvulsant & 1 \\
\hline $\begin{array}{l}\text { Urticarial vascu- } \\
\text { litis }\end{array}$ & & 1 & Ayurvedic & 1 \\
\hline Psoriasiform & & 1 & Antidiabetic & 1 \\
\hline Lichenoid & & 1 & ATT & 1 \\
\hline Erythroderma & 1 & & Anticonvulsant & 1 \\
\hline $\begin{array}{l}\text { Toxic epidermal } \\
\text { necrolysis }\end{array}$ & & 1 & $\begin{array}{l}\text { Ursodeoxycho- } \\
\text { lic acid acUDCA }\end{array}$ & 1 \\
\hline DRESS Syndrome & & 1 & $\begin{array}{l}\text { DMARD: Le- } \\
\text { flunomide }\end{array}$ & 1 \\
\hline Total & 10 & 92 & & 102 \\
\hline
\end{tabular}

Antibiotic was the most common drug to cause exanthematous drug reaction. Other drugs that caused exanthematous reactions were anticonvulsants, NSAIDs, antipsychotic, drugs used in management of gout (Allopurinol), mood stabilizer (Lithium) and DMARD. Antibiotic was also the most common etiology for urticarial drug eruption. Fixed drug eruption was most commonly caused by NSAIDs. Antibiotic was the second most common cause for fixed drug eruption. Photosensitivity was most commonly caused by NSAIDs followed by antibiotics and diuretic (Hydrochlorthiazide). SJS was most frequently caused by anticonvulsants. Other drugs associated with SJS were antibiotics and DMARD. Hair loss was caused by anticonvulsant, DMARD and anticoagulant. Pityriasis rosea was induced by proton pump inhibitor and antifungal. There were two cases of pigmentation and those were caused by antidepressants. There were two cases of pruritus caused by anticonvulsant and antitubercular treatment (ATT), one each. There was one case each of acute generalized exanthematous pustulosis (AGEP), caused by diuretic (amiloride), purpura caused by anticonvulsant, acneiform eruption caused by anticonvulsant, psoriasiform caused by antidiabetic, lichenoid drug reaction induced by ATT, Erythroderma caused by anticonvulsant, TEN caused by Ursodeoxycholic acid, DRESS (Drug rash eosinophilia and systemic symptoms) syndrome caused by DMARD and urticarial vasculitis caused by Ayurvedic drug (Table 4).

\section{DISCUSSION}

Drug reactions can be classified into immunologic and nonimmunologic etiologies, the most being caused by predictable, nonimmunologic effects ${ }^{3}$. It is very important to diagnose CADR as early as possible to prevent the morbidity and mortality from the reactions. The serious reactions can be fatal at times. We had followed the WHO causality definitions to categorize the CADR, as it is a very simple and widely accepted method.

The mean age of our patient was $32 \pm 15.7$ years, comparable to the finding of a Malaysian study ${ }^{4}$ but younger than that was seen in French ${ }^{5}$ and Italian studies ${ }^{6}$. A female preponderance was noticed in our study. Males were more commonly involved in several other studies ${ }^{5,7-11}$.

Majority of our patients were in the age group of 21 to 40 years which is comparable with other studies ${ }^{7,12}$. Lesser number of CADRs were observed in pediatric age group ( $<14$ years) in our study (10\%), which is similar to the findings of Dimri D et $a l^{12}$ and Gonzalez Martin G et $a l^{13}$. But some studies have suggested that CADR is more common in younger children and older adults, due to the dysfunctional immune system and inability to metabolize the drugs ${ }^{14}$. Old patients are involved in consumption of a large number of medications with increased incidence of drug reactions. Around seven percent of our patients were of more than 60 years of age.

A wide clinical spectrum of cutaneous adverse drug reactions was observed in our study. Altogether we observed 18 different types of cutaneous adverse drug reactions. Exanthematous type was the commonest type of reaction observed in our study which is in accordance to the finding of several other authors ${ }^{4,8,12,15-17}$. Fixed drug eruption was the second most common drug eruption seen in our study similar to the finding of Patel RM et $a l^{18}$. Pudukadan D et al have shown fixed drug eruption to be the most common type ${ }^{19}$.

Antimicrobials was the commonest drug category of drug involved in CADR observed by several authors $8,12,16$. Antibiotic was the most common cause of CADR in our study. This is similar to the finding of other authors ${ }^{7,9,17}$. Cefixime was the most common drug incriminated in CADR in our study. Cotrimoxazole was the most common cause of drug eruptions in other studies ${ }^{9,18,19}$. In our study, antibiotics were associated with both non serious as well as serious CADR like SJS. 
NSAIDs induced adverse events most frequently in a study of Kacalak-Rzepka A et $a{ }^{20}$. Anticonvulsants were responsible for the majority of CADRs in a study of Botelho LF et al in around 24\% of $\operatorname{cases}^{21}$. Antibiotics were implicated in the majority of exanthematous drug reactions (69\%) in our study. Sharma VK et al observed that anticonvulsant was the commonest group of drugs implicated in exanthematous reaction ${ }^{8}$. In our study, FDE was most frequently caused by NSAIDs. Sulfonamide was the commonest drug group implicated in FDE in the observation of Sharma VK et $a l^{8}$.

The overall incidence of CADR in our study was $0.32 \%$. This finding was similar to the finding of a French survey ${ }^{5}$. A higher incidence rate was reported in an Indian Study ${ }^{7}$. The reported incidence of CADR in Mid-Western Nepal was $1.6 \%$. Serious CADRs were found in around $9 \%$ of our cases. It was $24 \%$ in Mid-Western $\mathrm{Nepal}^{9}$. Tuchinda P et al observed serious CADR in $16.5 \%$ patients ${ }^{17}$. A higher incidence of serious CADR has been reported by other authors $^{5,7}$. We observed that SJS was the most common type of serious CADR, similar to the observation of other authors ${ }^{9,22}$. Anticonvulsant was the commonest drug group involved in serious CADR in our study. Anticonvulsants were also responsible for the serious CADR in other studies $^{8,21}$.

DRESS syndrome is one of the severe forms of CADR. The drugs incriminated in DRESS syndrome are anticonvulsants, allopurinol, sulphonamides and antibiotics $^{23}$. We had observed one case of DRESS syndrome that was caused by Leflunomide. DRESS syndrome caused by Leflunomide was also reported by Parajuli $S$ et $a l^{24}$. Dress syndrome was caused by allopurinol followed by carbamazepine in a study by Chiou CC et $a l^{25}$. Antibiotic was the main culprit drug for DRESS syndrome in a study by Skowron $\mathrm{F}$ et $\mathrm{al}^{26}$. We had observed one case of toxic epidermal necrolysis caused by ursodeoxycholic acid and one case of acute generalized exanthematous pustulosis (AGEP) caused by the diuretic, amiloride.

In our study, six patients (6\%) had previous CADR with the drug of similar category, four had recurrent FDE, one had exanthematous drug reaction and one patient got TEN for second time with ursodeoxycholic acid. Hence, drug preventability was noted to be six percent. Drug preventability has been reported in $15 \%$ in other study ${ }^{5}$.

\section{CONCLUSIONS}

The commonest type of CADR noted was exanthematous type. Antibiotic was the commonest drug group involved in CADR. Six percent of CADR were preventable.

\section{REFERENCES}

1. Roujeau JC, Allanore L, Liss Y, Mockenhaupt M. Severe cutaneous adverse reactions to drugs (SCAR): Definitions, diagnostic criteria, genetic predisposition. Dermatol Sinica. 2009; 27: 203-9.

2. The Uppsala Monitoring Centre. The use of the WHO UMC system for standardised case causality assessment. Available from: http://www.who.int/ medicines/areas/quality_safety/safety_efficacy/ WHOcausality_assessment.pdf. [Accessed on 2018 Mar 30].

3. Executive summary of disease management of drug hypersensitivity: A practice parameter. Joint Task Force on Practice Parameters, the American Academy of Allergy, Asthma and Immunology, and the Joint Council of Allergy, Asthma and Immunology. Ann Allergy Asthma Immunol. 1999; 83: 665-700.

4. Ding WY, Lee CK, Choon SE. Cutaneous adverse drug reactions seen in a tertiary hospital in Johor, Malaysia. Int J Dermatol. 2010; 49: 834-41.

5. Fiszenson-Albala F, Auzerie V, Mahe E, Farinotti $\mathrm{R}$, Durand-Stucco C, Crickx B, et al. A 6-month prospective survey of cutaneous drug reactions in a hospital setting. Brit J Dermatol. 2003; 149: 1018-22.

6. Naldi L, Conforti A, Venegoni M, Grazia Tronco M., Caputi, A, Ghiotto E, et al. Cutaneous reactions to drug: An analysis of spontaneous reports in four Italian regions. Br J Clin Pharmacol. 1999; 48: 839-46.

7. Sushma M, Noel MV, Ritika MC, James J, Guido S. Cutaneous adverse drug reactions: A 9-year study from a South Indian Hospital. Pharmacoepidemiol Drug Saf. 2005; 14(8): 567-70.

8. Sharma VK, Sethuraman G, Kumar B. Cutaneous adverse drug reactions: Clinical pattern and causative agents- a 6 year series from Chandigarh, India. $J$ Postgrad Med. 2001; 47(2): 95-9.

9. Neupane S, Sharma SR. Cutaneous adverse drug reactions: A 6-month Teaching Hospital based study 
from mid-Western Nepal. J Clin Diagn Res. 2012 May (Suppl-1); 6(3): 445-448.

10. Regnier S, Descamps V, Boui M, Lebrun-Vignes B, Descamps D, Grossin M, et al. Parvovirus B19 infection mimicking the drug-induced hypersensitivity syndrome. Ann Dermatol Venereol. 2000; 127: 505-6.

11. Rademaker M. Do women have more adverse drug reactions? Am J Clin Dermatol. 2001; 2(6): 349-51.

12. Dimri D, Raina RS, Thapliyal S, Thawani V. Retrospective analysis of pattern of cutaneous adverse drug reactions in Tertiary Hospital of Pauri Garhwal. J Clin Diagn Res. 2016; 10(5): FC01-6.

13. Gonzalez-Martin G, Caroca CM, Paris E. Adverse drug reactions (ADRs) in hospitalized pediatric patients. A prospective study. Int J Clin Pharmacol Ther. 1998; 36(10): 530-33.

14. Schmitt LC. Drug reactions in the elderly. Cutis 1988; 41: $58 \mathrm{e} 60$.

15. Hernández-Salazar A, Rosales SP, Rangel-Frausto S, Criollo E, Archer-Dubon C, Orozco-Topete R. Epidemiology of adverse cutaneous drug reactions. A prospective study in hospitalized patients. Arch Med Res. 2006; 37: 899-902.

16. Chattopadhyay C, Chakrabarti N. A cross-sectional study of cutaneous drug reactions in a private Dental College and Government Medical College in Eastern India. Niger J Clin Pract. 2012; 15(2): 194-8.

17. Tuchinda P, Chularojanamontri L, Sukakul T, Thanomkitti K, Nitayavardhana S, Jongjarearnprasert $\mathrm{K}$, et al. Cutaneous adverse drug reactions in the elderly: A retrospective analysis in Thailand. Drugs Aging. 2014; 31(11): 815-24.

18. Patel RM, Marfatia YS. Clinical study of cutaneous drug eruptions in 200 patients. Indian J Dermatol Venereol Leprol. 2008; 74(4): 430.

19. Pudukadan D, Thappa DM. Adverse cutaneous drug reactions: Clinical pattern and causative agents in a Tertiary Care Center in South India. Indian J Dermatol Venereol Leprol. 2004; 70(1): 20-4.

20. Kacalak-Rzepka A, Klimowicz A, Bielecka-Grzela S, Załuga E, Maleszka R, Fabiańczyk H. Retrospective analysis of adverse cutaneous drug reactions in patients hospitalized in Department of Dermatology and Venereology of Pomeranian Medical University in 1996-2006. Ann Acad Med Stetin. 2008; 54(2): 52-8.

21. Botelho LF, Porro AM, Enokihara MM, Tomimori J. Adverse cutaneous drug reactions in a single quaternary referral Hospital. Int J Dermatol. 2016; 55(4): e198-203.

22. Paudel U, Parajuli S, Pokhrel DB. Patterns and outcomes of cutaneous adverse drug reactions in a Hospital based study. Nepal Journal of Dermatology, Venereology and Leprology. 2017; 15(1): 44-8.

23. Kardaun SH, Sekula P, Valeyrie -Allanore L, Liss Y, ChuCY, Creamer D, et al. Drug reaction with eosinophilia and systemic symptoms (DRESS): An original multisystem adverse drug reaction. Results from the prospective RegiSCAR study. Br J Dermatol. 2013; 169: 1071-80.

24. Parajuli S, Chaudhari D, Pandey S, Baral S, Pokhrel DB. Leflunomide induced DRESS syndrome: A case report. Nepal Journal of Dermatology, Venereology and Leprology. 2012; 10: 46-8.

25. Chiou CC, Yang LC, Hung SI, Chang YC, Kuo TT, Ho HC, et al. Clinico-pathological features and prognosis of drug rash with eosinophilia and systemic symptoms: A study of 30 cases in Taiwan. J Eur Acad Dermatol Venereol. 2008; 22(9): 1044-9.

26. Skowron F, Bensaid B, Balme B, Depaepe L, Kanitakis J, Nosbaum A, et al. Drug reaction with eosinophilia and systemic symptoms (DRESS): Clinicopathological study of 45 cases. J Eur Acad Dermatol Venereol. 2015; 29(11): 2199-205. 